\title{
INLAND-LAKES PROTECTION APPLICATION WITH HIGH RESOLUTION SATELLITE IMAGERY IN WUHAN CITY
}

\author{
Xiongfei Wen ${ }^{\mathrm{a} *}{ }$, Zhe $\mathrm{Li}^{\mathrm{a}}$, Daxiang Xiang ${ }^{\mathrm{a}}$, Shaohong Shen ${ }^{\mathrm{a}}$, Dunmei Hu ${ }^{\mathrm{b}}$, Xiao Xiao ${ }^{\mathrm{a}}$ \\ ${ }^{\text {a }}$ Changjiang River Scientific Research Institute, Changjiang Water Resources Commission, Wuhan 430010, PR China- \\ xfwen19@163.com \\ ${ }^{\mathrm{b}}$ Department of Pharmacy, Tongji Hospital Affiliated with Tongji Medical College, Huazhong University of Science and Technology, \\ Wuhan, China 430032, PR China
}

KEY WORDS: Wuhan, Inland-lakes, ZY-3, GF-1, object-oriented, change detection

\begin{abstract}
:
The new data source of China's civilian high resolution earth observation system ZY-3, GF-1 were applied in the application of the monitoring and protection of the inland-lakes in Wuhan, Hubei Province. After the pre-process of these high resolution satellite images, the object-oriented classification and object-oriented change detection technology were applied in the inland-lakes protection of Wuhan, China. In this paper, the Xiwanhu Lake and Tangxunhu Lake including their surrounding areas were selected as an example, with the experiments the status of these lakes including the lake boundary, lake area and the change of these lakes including the lake water surface increased area, lake water surface decreased area were be obtained. Compared with the pixel-based method, the object-oriented classification and change detection technology shows its intuitive and higher precision in inland-lake protection. Remote sensing technology should be applied in monitoring and protection the inland-lake and other respects of water resource management more widely and deeply in China.
\end{abstract}

\section{INTRODUCTION}

\subsection{Background}

Wuhan is one of the mega cities in Central China. Wuhan is known as "the city with $100+$ inland-lakes", and currently there are 166 inland-lakes in Wuhan $(\mathrm{Hu}, 2013)$. While with the rapid development in social and economic during the past ten years, especially during the establishing the experimental zone 'Wuhan $1+8$ city cluster' since 2007 , which refers to a group with Wuhan as the core and a diameter of 100 kilometres, including Wuhan, and eight surrounding cities: Huangshi, Ezhou, Xiaogan, Huanggang, Xianning, Xiantao, Qianjiang and Tianmen. Many inland-lakes in Wuhan are in danger of being threatened status (some lakes were disappearing for some man-made factors such as land reclamation from lakes).

At the same time the Chinese government launched some highresolution civilian remote sensing satellites, including $\mathrm{ZY}-02 \mathrm{C}$, ZY-3, GF-1, with highest spatial resolution in panchromatic band could reach up to 2 meter and the spatial resolution of multispectral bands could reach to 5-10 meter which provides an ideal data source for the protection of inland-lakes in Wuhan.

\subsection{Study area introduction}

In this paper, the Xiwanhu Lake and Tangxunhu Lake, these two lakes of Wuhan including their surrounding areas were selected as an example to show the inland-lakes protection application with high resolution satellite imagery including monitoring the boundary and morphology for each lake by using the remote sensing technology. The satellite combined ground monitoring system by using the object-oriented classification technology, GPS technology, and information technology was developed. And the dynamic monitoring and the characteristic parameters of changes in lake's area and boundary were also be analyzed with multi-temporal remote sensing imagery. The location of Wuhan in China is shown in Figure 1.

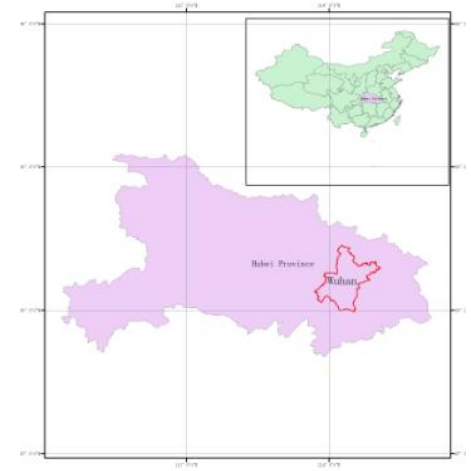

Figure 1. the Location of Wuhan in China

\subsection{Remote sensing imagery introduction}

The ZY-3 and GF-1 satellite imageries were collected as the main data source to apply in the application of the monitoring and protection of the inland-lakes in Wuhan.

ZY-3 satellite is the first civilian high spatial resolution optical transmission type three-line-array CCD stereo mapping satellite of China, which was launched on January 9th, 2012. ZY-3 is equipped with three high resolution panchromatic cameras (forward, backward and nadir cameras) and a multi-spectral camera. The ground resolution of the forward, backward and nadir camera is $3.5 \mathrm{~m}, 3.5 \mathrm{~m}$ and $2.1 \mathrm{~m}$ respectively. The

\footnotetext{
* Corresponding author: Xiongfei Wen, Tel.: +86-27-82926550; Fax.:+86-27-82820076
} 
resolution of the multispectral camera is $5.8 \mathrm{~m}$ operated in four spectral bands. With these three panchromatic cameras, the three different viewing angle stereo image pairs could be obtained (CRESDA, 2012).

The ZY-3 satellite weights $2650 \mathrm{~kg}$ with a design lifetime of 5 years. the satellite was built to acquire rapidly the continuous and stable high-resolution stereo images and multi-spectral images covering the whole country in a long term, serving land resources surveys and monitoring, disaster prevention and mitigation, agriculture and water conservancy, ecological environment, urban planning and construction, transportation plus national major projects. Currently, ZY-3 is performing at its top level. The technical specification of payloads and the orbital characteristics of ZY-3 is shown in Table 1 and Table 2.

\begin{tabular}{|c|c|c|c|c|c|}
\hline Payload & $\begin{array}{c}\text { Band } \\
\text { no. }\end{array}$ & $\begin{array}{c}\text { Spectral } \\
\text { range } \\
(\mu \mathrm{m})\end{array}$ & $\begin{array}{c}\text { Spatial } \\
\text { resolution } \\
(\mathrm{m})\end{array}$ & $\begin{array}{c}\text { Swath } \\
\text { width } \\
(\mathrm{km})\end{array}$ & $\begin{array}{c}\text { Side- } \\
\text { looking } \\
\text { ability }\end{array}$ \\
\hline forward & 1 & $0.5-0.8$ & 3.5 & 52 & $\pm 32^{\circ}$ \\
\hline backward & 1 & $0.5-0.8$ & 3.5 & 52 & $\pm 32^{\circ}$ \\
\hline nadir & 1 & $0.5-0.8$ & 2.1 & 51 & $\pm 32^{\circ}$ \\
\hline \multirow{5}{*}{ multispectral } & 1 & $\begin{array}{c}0.45- \\
0.52\end{array}$ & & & \\
\cline { 2 - 3 } & 2 & $\begin{array}{c}0.52- \\
0.59\end{array}$ & \multirow{2}{*}{8} & \multirow{2}{*}{51} & $\pm 32^{\circ}$ \\
\cline { 2 - 3 } & 3 & $\begin{array}{c}0.63- \\
0.69\end{array}$ & & & \\
\cline { 2 - 3 } & 4 & $\begin{array}{c}0.77- \\
0.89\end{array}$ & & & \\
\hline
\end{tabular}

Table 1. Technical specification of payloads of ZY-3

\begin{tabular}{|c|c|}
\hline Satellite & ZY-3 \\
\hline Orbit & $\begin{array}{c}\text { Sun synchronous recurrent frozen } \\
\text { orbit }\end{array}$ \\
\hline Altitude & $505.984 \mathrm{~km}$ \\
\hline Inclination & $97.421^{\circ}$ \\
\hline Repetition cycle & 59 days \\
\hline $\begin{array}{c}\text { Descending node (Local } \\
\text { time) }\end{array}$ & $10: 30 \mathrm{AM}$ \\
\hline
\end{tabular}

Table 2. Orbital characteristics of ZY-3

GF-1 satellite is the first of a series of the high-definition earth observation system (HDEOS) major special project (GF special project) of CNSA(China National Space Administration), China, which was launched on April 26, 2013. GF special project is one of the 16 major special projects in the 'Outline of the National Program for Long- and Medium-Term Scientific and Technological Development (2006-2020) of China'.

Developed by the China Academy of Space Technology, GF-1 is the first of five or six satellites to be launched between 2011 and 2016. GF-1 satellite owns the combined advantages of a high spatial resolution and wide view field. It is equipped with two solar panel wings. For observation purposes, GF-1 is equipped with a 2 meter resolution CCD camera, an 8 meter resolution multi-spectrum imager(PMS), and four $16 \mathrm{~m}$ multispectral medium resolution cameras(WFV), with width reaching $800 \mathrm{~km}$. The system could play an important role in disaster prevention and relief, climate change monitoring, geographical mapping, environment and resource surveying as well as precision agriculture. The technical specification of payloads and the orbital characteristics of GF-1 is shown in Table 3 and Table 4 (CRESDA, 2013).
GF-1 is of great strategic significance for promoting and enhancing China's satellite engineering standards, improving self-sufficiency rate of high-resolution imagery.

\begin{tabular}{|c|c|c|c|}
\hline Parameter & \multicolumn{2}{|c|}{ 2/8m PMS camera } & $\begin{array}{c}\text { 16m WFV } \\
\text { camera }\end{array}$ \\
\hline \multirow{5}{*}{$\begin{array}{l}\text { Spectral } \\
\text { range }(\mu \mathrm{m})\end{array}$} & PAN & $0.45-0.90 \mu \mathrm{m}$ & - \\
\hline & \multirow{4}{*}{ MSS } & $0.45-0.52 \mu \mathrm{m}$ & $0.45-0.52 \mu \mathrm{m}$ \\
\hline & & $0.52-0.59 \mu \mathrm{m}$ & $0.52-0.59 \mu \mathrm{m}$ \\
\hline & & $0.63-0.69 \mu \mathrm{m}$ & $0.63-0.69 \mu \mathrm{m}$ \\
\hline & & $0.77-0.89 \mu \mathrm{m}$ & $0.77-0.89 \mu \mathrm{m}$ \\
\hline \multirow{2}{*}{$\begin{array}{l}\text { Spatial } \\
\text { resolution } \\
(\mathrm{m})\end{array}$} & PAN & $2 \mathrm{~m}$ & \multirow[b]{2}{*}{$16 \mathrm{~m}$} \\
\hline & MSS & $8 \mathrm{~m}$ & \\
\hline $\begin{array}{l}\text { Swath } \\
\text { width } \\
(\mathrm{km})\end{array}$ & \multicolumn{2}{|c|}{$\begin{array}{c}\text { 60km (2 cameras } \\
\text { combine })\end{array}$} & $\begin{array}{l}800 \mathrm{~km}(4 \\
\text { cameras } \\
\text { combine) }\end{array}$ \\
\hline $\begin{array}{c}\text { Repetition } \\
\text { Cycle } \\
\text { (day) }\end{array}$ & \multicolumn{2}{|r|}{41} & 4 \\
\hline
\end{tabular}

Table 3. Technical specification of payloads of GF-1

\begin{tabular}{|c|c|}
\hline Satellite & GF-1 \\
\hline Orbit & $\begin{array}{c}\text { Sun synchronous recurrent } \\
\text { frozen orbit }\end{array}$ \\
\hline Altitude & $645 \mathrm{~km}$ \\
\hline Inclination & $98.0506^{\circ}$ \\
\hline Repetition cycle & $41 / 4$ days \\
\hline $\begin{array}{c}\text { Descending node (Local } \\
\text { time) }\end{array}$ & $10: 30 \mathrm{AM}$ \\
\hline
\end{tabular}

Table 4. Orbital characteristics of GF-1

ZY-3 satellite imageries collected is covering April, 2012, February, 2013, and GF-1 satellite imageries collected is covering April, 2013 and October, 2013. With these imageries, the changes of inland-lakes in Wuhan during the 2012 to the first half of 2013 and during the first half of 2013 to the second half of 2013 could be obtained.

\section{DATA PROCESS AND EXPERIMENTS}

\subsection{Remote sensing imagery pre-process}

The pre-process of ZY-3 and GF-1 satellite imagery contains the steps including unzip the raw data obtained from CRESDA (China Centre for Resources Satellite Data and Application), geometric correction/orthorectification with the RPC metadata file provided in the ZY-3/GF-1 raw imagery and the DEM file, radiation calibration with the calibration coefficient provide by CRESDA, image sharpening with the Gram-Schmidt pan sharpening algorithm by using the multispectral image with spatial resolution of 8 meter and the panchromatic image with spatial resolution of 2 meter (Jensen, 2004).

After the sharpening procedure, the $\mathrm{ZY}-3 / \mathrm{GF}-1$ images in the multi time-phase were registered with the API function provide in ENVI. The data pre-process is schematized in Figure 2, and this automated data process procedure has been implemented by using IDL(Interactive Data Language). 


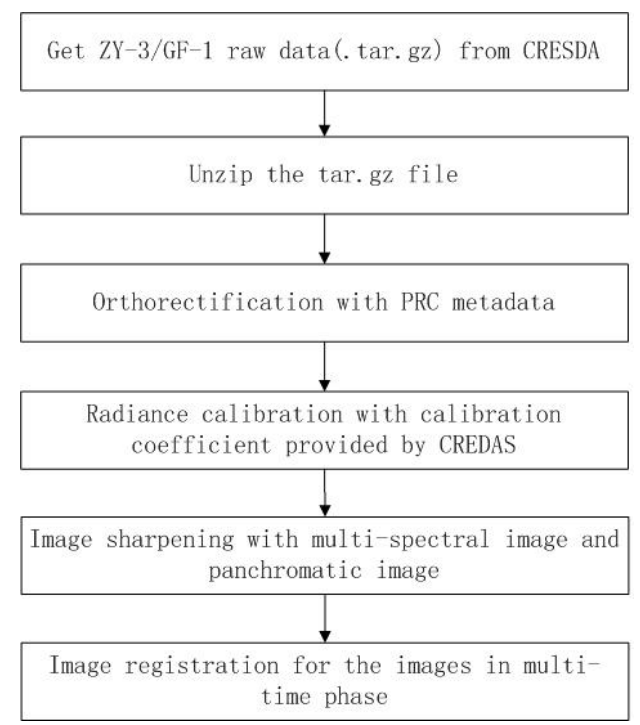

Figure 2. the Pre-process of ZY-3/GF-1 imagery

For the image covering Xiwanhu Lake of April 2012 after the pre-process including radiation calibration, image sharpening, image registration procedure, the eCognition software was selected to process multi-scale segmentation and object-oriented features extraction.

\section{ZY-3 Image of Xiwanhu Lake and its surrounding area}

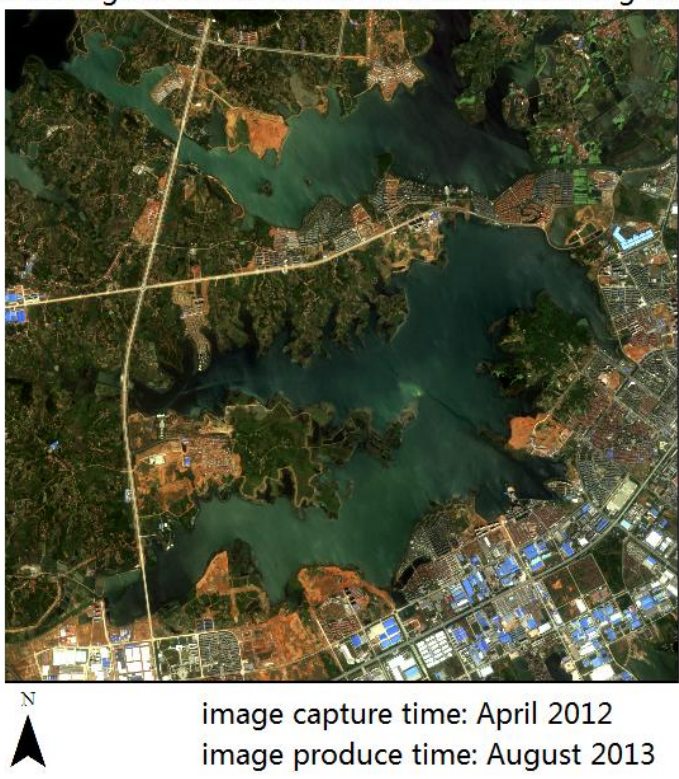

Figure 3. ZY-3 image of Xiwanhu Lake and its surrounding area

\subsection{Remote sensing imagery process in eCognition}

Considering the actual situation in Xiwanhu Lake and its surrounding area and the resolution of remote sensing imagery. we selected the water body, vegetation, buildings, bare land, and roads to classify. Through the observation of the experimental area found Xiwanhu Lake and its surrounding area, the feature characterized for each class is described below:

1. water body: the spectral feature is shown in dark green (in the true colour composite image), the texture feature is overall smooth and with the obvious boundary.
2. vegetation: the spectral feature is shown in light green (in the true colour composite image ) with the overall coarse texture feature.

3. buildings: the spectral feature is shown in gray-white colour (some roof of the building is in blue) with the relatively regular geometric shape.

4. bare land: the spectral feature is shown in khaki colour with small in area.

5. roads: the spectral feature is shown in gray-white colour with the linear shape.

After determines the features for each class, the eCognition software is applied by segmenting the input imagery with different segmentation scale and parameters setting.

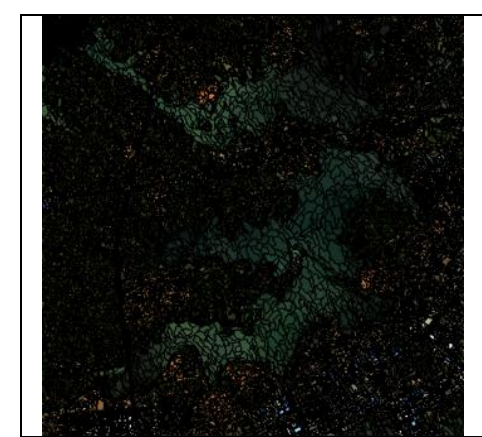

(a)

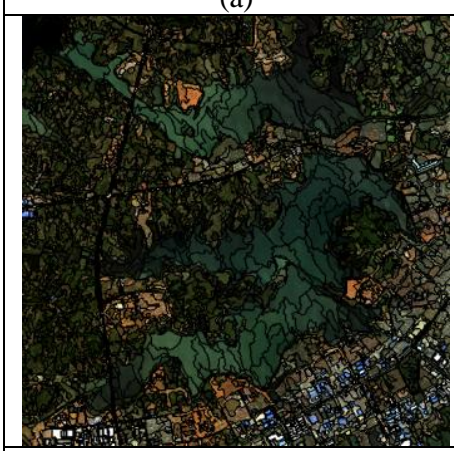

(c)

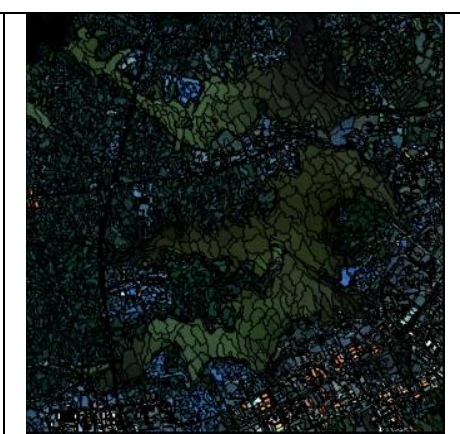

(b)

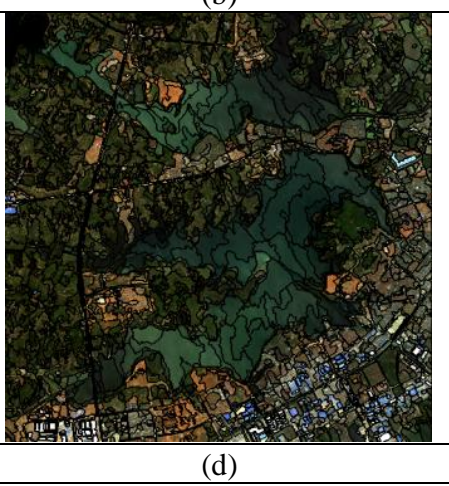

(d)
Figure 4. Segmenting ZY-3 imagery with different segmentation scale and parameters setting, (a) scale parameter $=20$, shape $=0.1$, compact $=0.5$, (b) scale

parameter $=40$, shape $=0.2$, compact $=0.5$, (c) scale parameter $=20$, shape $=0.1$, compact $=0.5$, (d) scale parameter $=40$, shape $=0.2$, compact $=0.5$

According to Drăguţ's research (L Drăguţ,2010), the suitable segmenting scale parameters could be obtained using the ESP tool in eCognition by considering the local variance of object heterogeneity within a scene, while in our work, the ESP tool did not show its superiority. In this paper, the proper segmenting scale and parameters is determined by trial - error and the human computer interaction.

After determination the proper scale parameter for the input imagery, the input imagery could be segmented and each object in the imagery could be accessed. With each object in the segmented imagery, the samples for each class could be selected, and the combined with the feature character for each class, the classifier could be built by using the CART classification algorithm, and then the classification thematic map could be 
obtained by applying the classifier, the thematic map is shown in figure 5 .

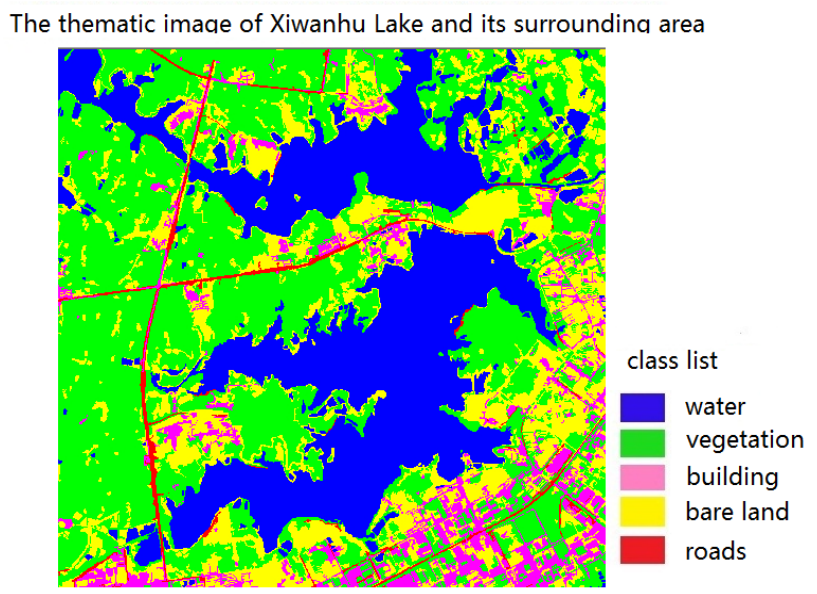

image capture time: April 2012

$$
\text { A image produce time: August } 2013
$$

Figure 5. The thematic image of Xiwanhu Lake and its surrounding area

The classification procedure of remote sensing imagery covering Tangxunhu Lake is processed in the same way that the Xiwanhu Lake was processed. And after the extracting the water class in Tangxunhu lake in eCognition during April 2012 to April 2013 respectively. The change of Tangxunhu lake could be obtained by applying the Copy map and Synchronize Map in eCognition with remote sensing in different year. and change detection procedure and the change detection thematic map could be obtained in figure 6 and figure 7. in figure 7, the lake regions where water had decreased, increased, not changed were obtained and displayed in different colors (red, yellow and blue respectively ) on the thematic map (Trimble, 2014).

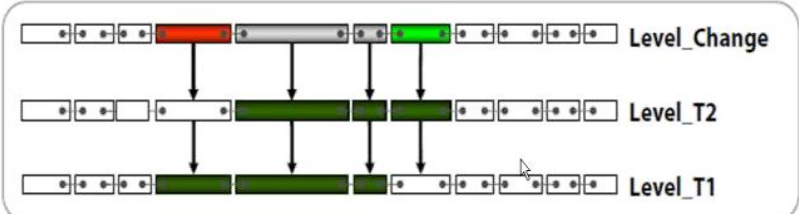

Figure 6. The change detection procedure in eCognition

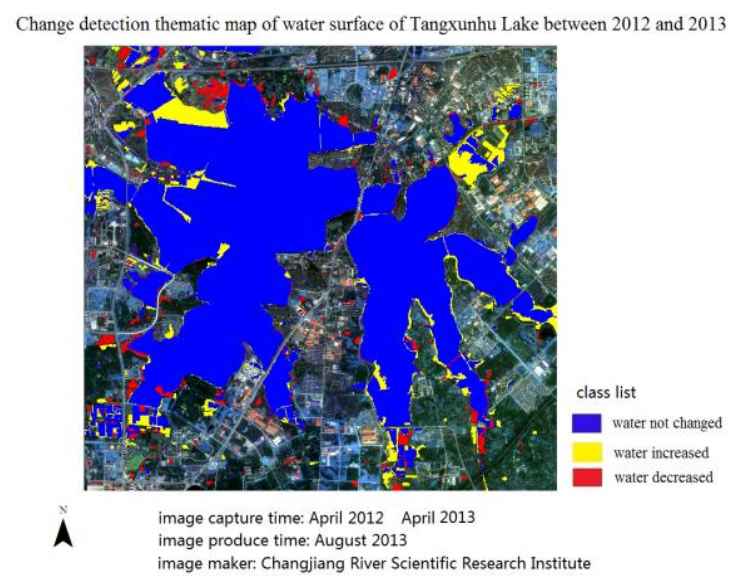

Figure 7. The change detection thematic map of water surface of Tangxunhu Lake between 2012 and 2013

\section{Results and Conclusion}

In this paper, the new data source of China (ZY3/GF1) was selected in inland-lake monitoring and protection. With these high spatial resolution satellite imagery, the object-oriented analysis method is applied in inland-lakes boundary extraction by the object-oriented classification in eCognition. Based on the ZY-3 imagery captured in April 2012, the classification map of Xiwanhu Lake is produced, and based on the imagery between April 2012 (ZY-3) and April 2013 (GF-1), the water surface change thematic map of Tangxunhu Lake in Wuhan is also be obtained efficiently and clearly. While the important point should be noted is that although the change area were found by satellite imagery, while the detailed reason for the change of water surface should be validated and checked by the field survey and investigation. some change maybe the false change for the spectral difference cause by the weather or other factors. With the rapid development in Wuhan, especially in establishing the experimental zone 'Wuhan $1+8$ city cluster', many lakes are changed from water surface to land surface, and this situation is really a challenges for water resource management in Wuhan. While the rapid developing remote sensing technology in China shown as the improvement in the spatial/temporal resolution, satellite imagery could be a kind of new data source or solution in water resource management. The works in this paper illustrates this point in certain extent.

\section{ACKNOWLEDGEMENTS}

This work was funded through a grant from the National Scientific Fund of China (No. 41201452, No. 41409021, No. 41401487) and the Basic Research Operating Expenses for the Central-level Non-profit Research Institutes of China (No. CKSF2015018/KJ, No. CKSF2015019/KJ). The authors would like to thank the staff of the China Centre for Resources Satellite Data and Application (CRESDA) for their support.

\section{REFERENCES}

\section{References}

[1] Hu, L., 2013, The Lakes in Wuhan, Wuhan: Wuhan Press.

[2] China centre for resources satellite data and application, 2012, China centre for resources satellite data and application ZY-3 science data users handbook, Beijing.

[3] China centre for resources satellite data and application, 2013, China centre for resources satellite data and application GF-1 science data users handbook, Beijing.

[4] Jensen, J., Introductory Digital Image Processing: A Remote Sensing Perspective(3rd Edition), Prentice Hall Press, Minnesota 2004.

[5] Drăguţ, L., Tiede,D., Shaun, R. 2010. ESP: a tool to estimate scale parameter for multiresolution image segmentation of remotely sensed data, International Journal of Geographical Information Science, Vol. 24, Iss. 6, 859-871.

[6] Trimble, 2014. eCognition Developer 9 User Guide, Trimble Germany GmbH, München, Germany. 